\title{
DETECTION OF CARBONYL FLUORIDE IN THE STRATOSPHERE
}

\author{
C.P. Rinsland ${ }^{1}$, R. Zander ${ }^{2}$, L.R. Brown ${ }^{3}$, C.B. Farmer ${ }^{3}$, J.H. Park ${ }^{1}$, \\ R.H. Norton ${ }^{3}$, J.M. Russell III ${ }^{1}$, and O.F. Raper ${ }^{3}$ \\ ${ }^{1}$ Atmospheric Sciences Division, NASA Langley Research Center \\ 2Institute of Astrophysics, University of Liege, Belgium \\ ${ }^{3}$ Jet Propulsion Laboratory, California Institute of Technology
}

Abstract. Inf rared solar absorption spectra of the stratosphere recorded at a resolution of $0.01 \mathrm{~cm}^{-1}$ by the ATMOS (Atmospheric Trace Molecule Spectroscopy) Instrument from onboard spacelab 3 $(04 / 30$ to $05 / 6 / 85)$ have revealed the existence of many previously unobserved absorption features in the 1925 to $1960 \mathrm{~cm}^{-1}$ and 1249 to $1255 \mathrm{~cm}^{-1}$ regions and one at $774 \mathrm{~cm}^{-1}$. On the basis of comparisons with laboratory spectra, these features have been identified as belonging to the $v_{1}, v_{4}$, and $v_{6}$ bands of carbonyl fluoride, respectively. Volume mixing ratios of $\mathrm{COF}_{2}$ between 17 and $40 \mathrm{~km}$ have been deduced from analysis of the $v_{1}$ and $v_{6}$ bands.

\section{Introduction}

During its first mission onboard Spacelab 3 (SL3), April 30 to May 6, 1985, the ATMOS (Atmospheric Trace Molecule Spectroscopy) instrument recorded more than 3000 inf rared solar spectra with a spectral resolution of $0.01 \mathrm{~cm}^{-1}$. About 2000 of these are "high sun" scans containing only solar features (absorption and emission). The remaining ones, recorded over long atmospheric limb paths during 12 sunsets and 5 sunrises with tangent heights ranging from 10 to $150 \mathrm{~km}$, contain a wealth of absorption features arising from several dozen gaseous constituents of the earth's atmosphere. In the present letter, we report the first stratospheric measurement of $\mathrm{COF}_{2}$ from analys is of its absorption features near $1937 \mathrm{~cm}^{-1}$ and $774 \mathrm{~cm}^{-1}$ with the additional identification of features near $1250 \mathrm{~cm}^{-1}$. The importance of this molecule lies in the fact that it has been postulated to be an intermediate product of the decomposition of chlorofluorocarbons (CFC's) in the upper atmosphere [Rowland and Molina, 1975; Sze, 1978].

\section{Data and Analysis}

The ATMOS instrument consists basically of a double-pass Michelson interferometer, a telescope, a suntracker, and a cooled $(77 \mathrm{~K}) \mathrm{HgCdTe}$ detector; details of the instrument and its operation during the SL3 mission have been described elsewhere [Farmer and Raper, 1986]. Successive millionpoint, double-sided interferograms were recorded from about $360 \mathrm{~km}$ altitude in 2.2 seconds, corresponding to a tangent height separation of $\sim 4.1$ $\mathrm{km}$. During each occultation, the data were

This paper is not subject to U.S. copyright. Published in 1986 by American Geophysical Union.

Paper number 6L6174.

0094-8276/86/006ł-6174\$03.00 collected using one of six overlapping broadband filters, covering altogether the 600 to 4700 $\mathrm{cm}^{-1}$ spectral region. The spacecraft ephemeris and measurements of sultable atmospheric absorption features (e.g. $\mathrm{CO}_{2}$ vibration-rotation and $\mathrm{N}_{2}$ quadrupole lines) have been used to determine the tangent heights of the spectra to better than $1 \mathrm{~km}$.

As the atmospheric absorption of $\mathrm{COF}_{2}$ is relatively weak, its detection and subsequent analy$s$ is by spectroscopic techniques require good knowledge of molecular line parameters of both the target and interfering gases. For example, Figure 1 reproduces excerpts from two observed ATMOS spectra along with two spectra computed to correspond with the bottom observed one; the four traces are displayed with the same scale, but offset from one another for clarity. The top spectrum is an average of 46 high sun scans recorded from an orbital altitude of $360 \mathrm{~km}$ near $26^{\circ} \mathrm{N}$ lat., $54^{\circ} \mathrm{W}$ long.; it contains only features of solar Co. The next lower trace is a synthetic spectrum computed from $\mathrm{COF}_{2}$ paraneters (described later) using an adjusted concentration profile obtained from model predictions (L. Froldevaux, private communication, 1985). The trace labeled "Calc." is a computed atmospheric spectrum based on line parameters similar to those of the AFGL compilations [Rothman et al., 1983a,b] with no $\mathrm{COF}_{2}$ included. The bottom spectrum, an observed ATMOS scan corresponding to a tangent height of $20.8 \mathrm{~km}$, is seen to be the composite of the upper three spectra; the presence of $\mathrm{COF}_{2}$ features, indicated by tick marks, is clearly evident.

Improvements to existing parameters in the AFGL compilations were necessary prior to the present analysis. Near $1937 \mathrm{~cm}^{-1}$, new values for $\mathrm{CO}_{2}$ [Rinsland et al., 1983, 1985], and $\mathrm{H}_{2} \mathrm{O}$ (R. Toth, private communication, 1986) were adopted, while changes in $\mathrm{CO}_{2}$ and $\mathrm{O}_{3}$ line parameters in the vicinity of $774 \mathrm{~cm}^{-1}$, which were made as a prerequisite for quantitative investigations of $\mathrm{Cl}^{\circ} \mathrm{ONO}_{2}$ at $780.2 \mathrm{~cm}^{-1}$ [Zander et a1., 1986] and of $\mathrm{HO}_{2} \mathrm{NO}_{2}$ near $802.7 \mathrm{~cm}^{-1}$ [Rinsland et al., 1986], were also included here.

At the outset of this work, parameters of $\mathrm{COF}_{2}$ similar in quality to those of other molecular species had not been published for the bands observed by ATMOS. There existed published spectral plots [Murcray and Goldman, 1981; Murcray et al., 1984], vibrational band assignments for the fundamentals [Mallinson et al., 1975], measurements for integrated band strengths [Hopper et al., 1968; Adams et al., 1971; Modica and Brochu, 1969l, and ground state parameters based on microwave data [Carpenter, 1974]. However, no high resolution line-by-line analyses of the $v_{1}, v_{4}$, and $v_{6}$ fundamentals were avallable. 


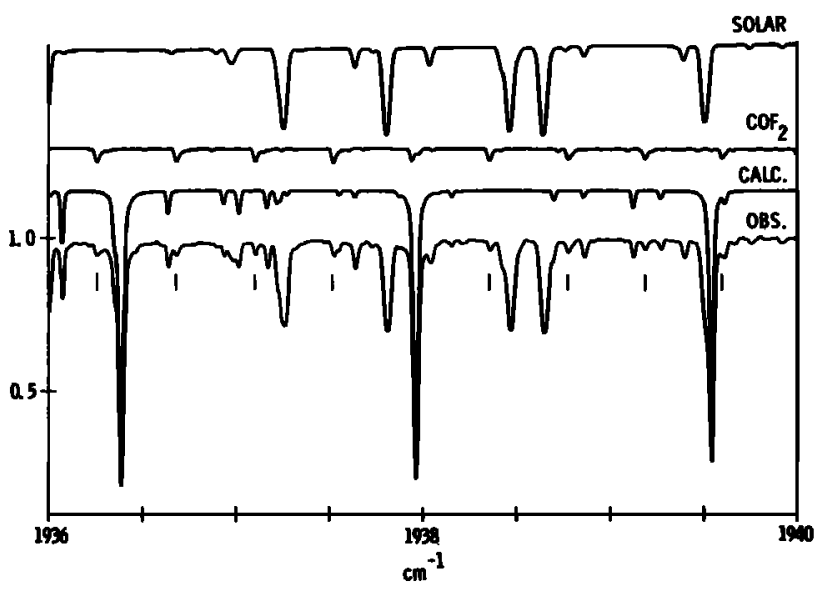

F1g. 1. The first detection of stratospheric $\mathrm{COF}_{2}$. The four spectra are an ATMOS high sun (SOLAR), a synthetic $\mathrm{COF}_{2}$, a synthetic stratospheric spectrum without $\mathrm{COF}_{2}$ (CALC.), and an ATMOS spectrum at $20.8 \mathrm{~km}$ (see text for details). The absorptions of $\mathrm{COF}_{2}$ are indicated by tick marks.

As a result, this study has had to rely on interim parameters of limited absolute accuracy, particularly for line strengths. In turn, this lack of data has required that retrievals of stratospheric mixing ratios versus altitude be done in two different ways, one method using equivalent widths, and the other fitting the shapes of spectral features, depending on the wavelength region considered.

For the 1925 - $1965 \mathrm{~cm}^{-1}$ region containing transitions of the $v_{1}$ fundamental, we have utilized line positions from a laboratory spectrum recorded at $0.01 \mathrm{~cm}^{-1}$ resolution with the McMath Fourier transform spectrometer (FTS) at the National Solar Observatory on Kitt Peak. Line positions have been calibrated using $\mathrm{H}_{2} \mathrm{O}$ standards [Brown and Toth, 1985]. With these, numerous weak features of $\mathrm{COF}_{2}$ were identified in the ATMOS data (Figure 1). As seen in Table 1 , positions determined by taking first and second derivatives of both laboratory and atmospheric features of $\mathrm{COF}_{2}$ agree in all cases to within $0.002 \mathrm{~cm}^{-1}$; this agreement is within the combined uncertainties of the ATMOS and laboratory positions, considering that each feature may represent several unresolved transitions. Line

Table 1. Positions of selected $\mathrm{COF}_{2}$ features in $\mathrm{cm}^{-1} \star *$

\begin{tabular}{ccc}
\hline ATMOS & Laboratory & ATMOS - Lab \\
\hline & & \\
1936.2570 & 1936.2587 & -0.0017 \\
1936.6821 & 1936.6820 & 0.0001 \\
1937.1038 & 1937.1037 & 0.0001 \\
1937.5232 & 1937.5218 & 0.0014 \\
1938.3580 & 1938.3567 & 0.0013 \\
1938.7750 & 1938.7736 & 0.0014 \\
1939.1857 & 1939.1872 & -0.0015 \\
\hline
\end{tabular}

** determined from first and second derivatives of the apodized spectra
Table 2. Experimental line parameters of $\mathrm{COF}_{2}$ used in this analysis*

\begin{tabular}{lccccc}
\hline POSITION & $\mathrm{S}$ & POSITION & $\mathrm{S}$ & POSITION & $\mathrm{S}$ \\
\hline & & & & & \\
\hline 1936.1970 & 0.32 & 1936.4863 & 0.55 & 1936.8465 & 0.49 \\
1936.2130 & 1.42 & 1936.5056 & 1.98 & 1936.8679 & 2.88 \\
1936.2298 & 1.26 & 1936.5201 & 0.82 & 1936.8806 & 1.34 \\
1936.2533 & 9.16 & 1936.5518 & 0.19 & 1936.9369 & 0.71 \\
1936.2643 & 8.84 & 1936.5791 & 0.82 & 1936.9507 & 0.94 \\
1936.2814 & 3.25 & 1936.5940 & 0.59 & 1936.9751 & 1.18 \\
1936.2936 & 1.31 & 1936.6132 & 1.56 & 1936.9900 & 0.73 \\
1936.3055 & 2.14 & 1936.6277 & 1.00 & 1937.0344 & 1.49 \\
1936.3164 & 1.64 & 1936.6781 & 10.70 & 1937.0482 & 0.91 \\
1936.3306 & 1.87 & 1936.6895 & 7.06 & 1937.0661 & 0.50 \\
1936.3366 & 0.88 & 1936.7046 & 3.53 & 1937.0991 & 9.18 \\
1936.3574 & 2.07 & 1936.7222 & 2.05 & 1937.1091 & 7.78 \\
1936.3816 & 1.37 & 1936.7384 & 2.24 & 1937.1209 & 1.21 \\
1936.4076 & 0.67 & 1936.7523 & 1.59 & 1937.1279 & 2.07 \\
1936.4195 & 1.16 & 1936.7757 & 0.65 & 1937.1441 & 2.50 \\
1936.4499 & 1.02 & 1936.7848 & 2.48 & 1937.1558 & 2.24 \\
1936.4705 & 0.94 & 1936.8136 & 0.30 & 1937.1791 & 2.32
\end{tabular}

* line positions are given in units of $\mathrm{cm}^{-1}$ and strengths in $S$ units of $\mathrm{cm} /$ molecule $\times 10^{-20}$ at room temperature

strengths at room temperature were also obtained from the Kitt Peak laboratory data using a nonlinear least squares procedure [Brown et al., 1983]. However, since assignments were unava11able, manifold heads were artificially represented as a smaller number of lines than is actually present. In addition, because of the rapid chemical decomposition of the sample, the absolute strengths were unreliable. Therefore, observed relative strengths were normalized to conform to a mean of three integrated band strengths [Hopper et al., 1968; Adams et al., 1971 ; Modica and Brochu, 1969], with the additional assumptions that $80 \%$ of this mean value belongs to $v_{1}$ (the remainder to a nearby overtone band, $2 v_{2}$ ) and that the interval between 1936.5 and $1939.4 \mathrm{~cm}^{-1}$ contains about $5 \%$ of the total strength of the band ( $\mathrm{K} . \mathrm{B}$. Thakur, private communication, 1986). A later check of the normalization was made using more recent Kitt Peak laboratory data. The absolute accuracies of the resulting strengths is thought to be $25 \%$. The individual line parameters finally adopted are given in Table 2.

These parameters were used in a curve-fitting procedure to retrieve the values of the stratospheric volume mixing ratio of $\mathrm{COF}_{2}$. Airbroadened half widths and lower state energies were set to $0.1 \mathrm{~cm}^{-1} / \mathrm{atm}$ at $296 \mathrm{~K}$ and $120 \mathrm{~cm}^{-1}$, respectively. For the analysis, we used a set of zonal average spectra covering the 1100 to $2000 \mathrm{~cm}^{-1}$ region, obtained by coadding the runs from three sunset occultations occuring near $32^{\circ} \mathrm{N}, 69^{\circ} \mathrm{E} ; 31^{\circ} \mathrm{N}, 92^{\circ} \mathrm{W}$; and $26^{\circ} \mathrm{N}, 54^{\circ} \mathrm{W}$ with approximately equal tangent heights of 38.5 , $34.5,30.5,26.8,23.5,20.4$, and $17.7 \mathrm{~km}$; these spectra had intially been ratioed to a coadded "high sun" solar spectrum. Special emphasis was given to the optimum fitting of the ATMOS zonal spectra between 1936.1 and $1937.2 \mathrm{~cm}^{-1}$, where three $\mathrm{COF}_{2}$ features appear relatively free of 

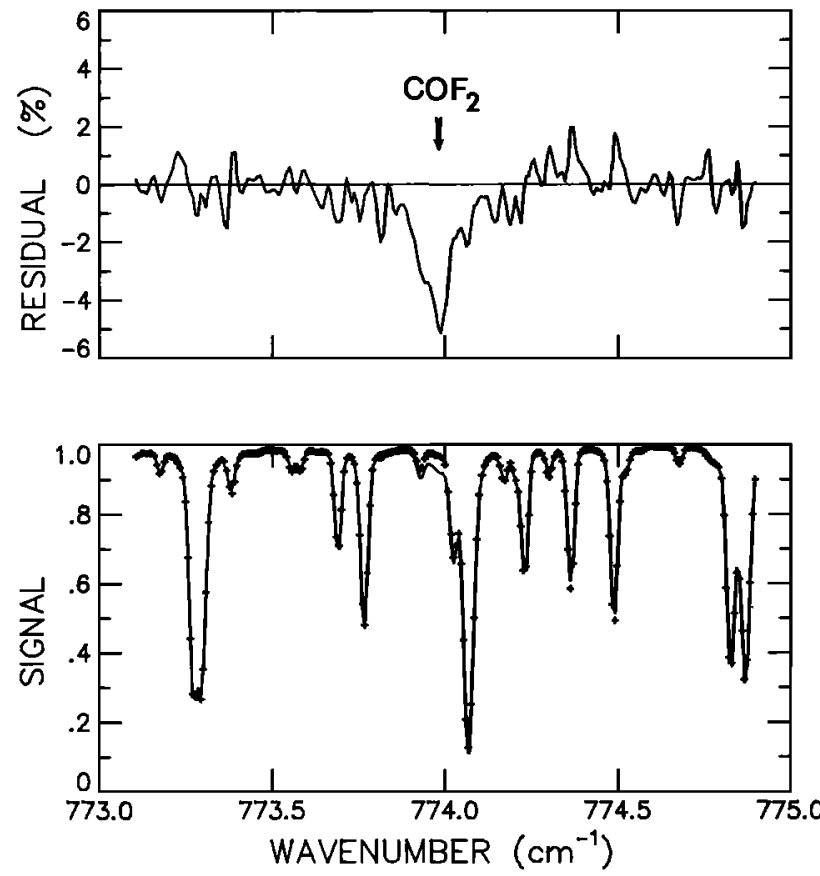

Fig. 2. Fitting results for an ATMOS spectrum in the region of the $v_{6}$ band $Q$ branch. The measured spectrum (solld line), produced by averaging spectra recorded at a tangent height of 25.5 $\mathrm{km}$ during 3 sunset occultations (1at. 30-33 N), and the best-fit calculated spectrum (crosses) are plotted beneath the residuals (observedcalculated). An arrow marks the location of the strongest absorption by the $\mathrm{COF}_{2} \mathrm{Q}$ branch.

any interferences by other telluric absorptions. The resulting volume mixing ratio (VMR) profile deduced from these fittings is represented by the solid curve in Figure 3.

Analysis of $\mathrm{COF}_{2}$ using the $v_{6}$ band at 774 $\mathrm{cm}^{-1}$ required a different approach because no line parameters were available there, and the band occurs in a region of relatively strong absorption by stratospheric $\mathrm{O}_{3}$ and $\mathrm{CO}_{2}$. Therefore, to detect its absorption, only the lines of the interfering molecules were included in calculations of the expected spectrum in this region, in the absence of COF 2. Figure 2 illustrates this procedure. In the top pane1, the weak residual absorption peak at $774.00+0.02 \mathrm{~cm}^{-1}$ is in good agreement with the $Q$ branch of $v_{6}$ observed at $773.987 \pm 0.005$ $\mathrm{cm}^{-1}$ (S., P. Sander and R. R. Friedi, private communication, 1986) in recent laboratory spectra of $\mathrm{COF}_{2}$ recorded at $0.005 \mathrm{~cm}^{-1}$ resolution. An analysis of these laboratory data is in progress to obtain accurate positions and assignments for the $\nu_{6}$ band $(\mathrm{K} . \mathrm{B}$. Thakur, private communication, 1986). Following identification, VMR profiles of $\mathrm{COF}_{2}$ were obtained by measuring the equivalent widths of the residual curve (e.g. Figure 2). To obtain the integrated intensity of this $Q$ branch, laboratory spectra were recorded at $0.06 \mathrm{~cm}^{-1}$ resolution and at room temperature with a Nicolet FTS and a sample of $99 \%$ pure $\mathrm{COF}_{2}$, purchased from SCM Specialty Chemfcals, Gainesville, Fla. The spectra were recorded within 1 month of receipt of the cylinder to minimize the slow decomposition in the container noted by Adams et a1. [1971]. The derived integrated 0 -branch intensity of $1.47+0.22 \times 10^{-18}$ $\mathrm{cm} / \mathrm{molecule}$ was extrapolated on the basis of the observed decay rate of the absorption (approximately 2\% per hour) to the time the absorption cell (made of Pyrex with KCl wedged windows and Teflon valves) was filled. Decomposition of $\mathrm{COF}_{2}$ is believed to result from reaction with $\mathrm{H}_{2} \mathrm{O}$ outgassing from the cell walls. Carbon dioxide was identified as a decomposition product by its absorption between 2200 and $2400 \mathrm{~cm}^{-1}$. Assuming the integrated $v_{6}$ Q-branch intensity noted above, linear absorption by $\mathrm{COF}_{2}$ in the atmospheric spectra, and correlative pressure-temperature profiles derived from a set of $\mathrm{CO}_{2}$ lines measured by ATMOS, we have deduced the profile represented by the dotted line in Figure 3.

Numerous weak features of the $v_{4}$ band have also been identified in the $1249-1254 \mathrm{~cm}^{-1}$ region. Because of strong Interference by $\mathrm{CH}_{4}, \mathrm{~N}_{2} \mathrm{O}, \mathrm{CO}_{2}$, and $\mathrm{H}_{2} \mathrm{O}$ lines in this interval, and the lack of complete $\mathrm{COF}_{2}$ line parameters, these features are less suitable for quantitative analysis than those in the other regions.

\section{Results and D1scussion}

The $\mathrm{COF}_{2}$ volume mixing ratios are given versus altitude in Figure 3. They constitute the first measurement of $\mathrm{COF}_{2}$ in the stratosphere; since many of the strongest absorption features of that molecule have been simultaneously observed in the ATMOS spectra, its detection is unambiguous. The values obtained from both the least squares fitting of lines belonging to the $v_{1}$ fundamental of $\mathrm{COF}_{2}$ (dark solid line) and from equivalent width measurements of its $v_{6} Q$ branch (dark dotted Ifne) are shown. The difference between these two curves (as high as a factor of 1.5 below $30 \mathrm{~km}$ ) is not 1ikely to be attributable to the fact that they were retrieved from two different sets of zonal average spectra; the latitudes and

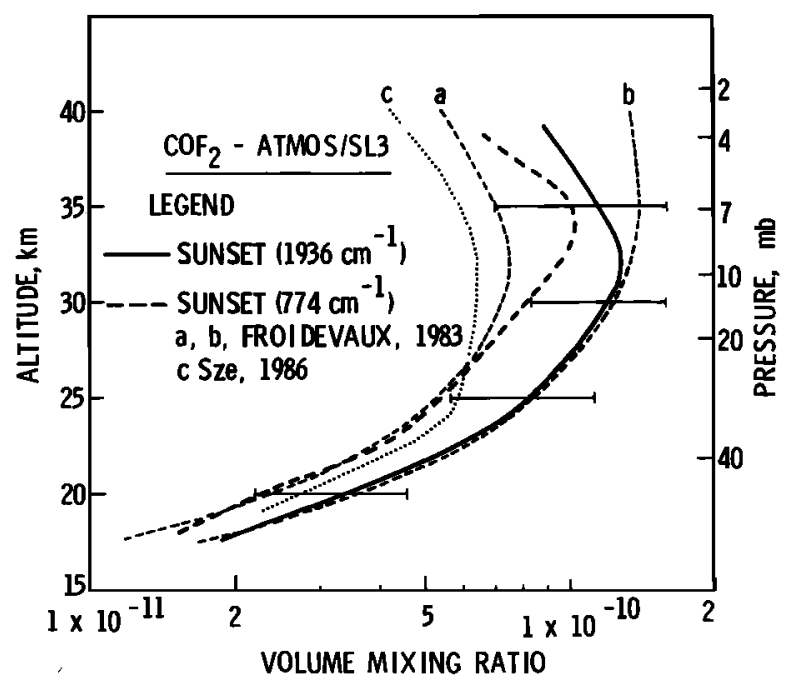

Fig. 3. Volume mixing ratios of carbonyl fluoride derived from ATMOS sunset spectra, using lines belonging to the $v_{1}$ band (heavy full line) and the $v_{6} Q$ branch (heavy dotted line). Model predictions by Froldevaux [1983] and by Sze (private communication, 1986) are reproduced for comparison (for details, see text). 
longitudes of the individual occultations were not markedly different. Rather, we suspect the absolute values of the strengths involved in both spectral regions used for the retrievals to be in question; future work on laboratory spectra is likely to provide a clue to that discrepancy.

The potential sources of both random and systematic errors and the resulting uncertainties in the COF 2 volume mixing ratios (values between parentheses) are (1) in curve fitting of the 1936 $\mathrm{cm}^{-1}$ features ( 10 to $40 \%$ ) or equivalent width measurements of the $v_{6} Q$ branch ( 10 to $50 \%$ ), (ii) in the tangent height altitudes (15\%), (iii) in the pressure-temperature profiles adopted (10\%), (iv) In the simulation of interfering lines In the $v_{6} Q$ branch region (20\%), and (v) in the $v_{1}$ strengths $(25 \%)$ or the $\nu_{6} Q$ branch strength (15\%). The resulting total uncertainties ( 1 sigma) range from $50 \%$ above $37 \mathrm{~km}$ to $32 \%$ at $20 \mathrm{~km}$ for the $1936 \mathrm{~cm}^{-1}$ region and from $58 \%$ above $37 \mathrm{~km}$ to $33 \%$ at $20 \mathrm{~km}$ for the $774 \mathrm{~cm}^{-1} \mathrm{Q}$ branch. For clarity in Figure 3, we have only reproduced the error bars for the full curve.

Model calculations by Froidevaux [1983] (curves $a$ and $b$ ) and by Sze (private communication, 1986) (curve c), all computed for Apri1, $30^{\circ} \mathrm{N}$, show the range of volume mixing ratios predicted by adoptIng a quantum yield for the photolysis of $\mathrm{COF}_{2}$ equal to 1 (curve a) or 0.25 (curve b), as well as differences in the predicted profiles for a $\mathrm{COF}_{2}$ photolysis yield of 1 (e.g., curve a versus curve c). Nonetheless, considering the uncertainties in both observational and theoretical results, it can be concluded that the agreement is reasonably good. Retrievals made for a sunrise occultation at $47^{\circ} \mathrm{S}$ have produced results similar to those found at northern latitudes; slightly larger concentrations were found below $30 \mathrm{~km}$, but it is premature to speculate about their significance, owing to the large uncertainties involved. The present observational data, supplemented by additional laboratory work on $\mathrm{COF}_{2}$ and by further observations from future ATMOS missions, should help in establishing both the quantum yield for COF $_{2}$ photolysis in the stratosphere and lat1tudinal varlations in its profile.

Acknowledgments. The research reported here was performed at the Jet Propulsion Laboratory, California Institute of Technology, under contract with the National Aeronautics and Space Administration. We are grateful to H. Pickett, R. A. Toth, R. Friedl, S. P. Sander, K. B. Thakur, G. A. Harvey, and V. Malathy Devi for making avallable the results of laboratory studies prior to publication. We also thank L. Froidevaux and N. D. Sze for providing model stratospheric profiles of $\mathrm{COF}_{2}$ for comparison with the ATMOS experimental results.

\section{References}

Adams, T. N., D. M. Weston, and R. A. Matula, Temperature dependence of the spectral intensity of the Fermit resonant $1943 \mathrm{~cm}^{-1}$ band of carbonyl fluoride, J. Chem. Phys., 55, 5674-5680, 1971 .

Brown, L. R., and R. A. Toth, Comparison of the frequencles of $\mathrm{NH}_{3}, \mathrm{CO}_{2}, \mathrm{H}_{2} \mathrm{O}, \mathrm{N}_{2} \mathrm{O}, \mathrm{CO}$ and $\mathrm{CH}_{4}$, J. Opt. Soc. Am. B, 2, 842-856, 1985.

Brown, L. R., et al., Computer-assisted measurement of line strengths with application to the methane spectrum, App1. Spectrosc., 37, $287-291,1983$.
Carpenter, J. H., The microwave spectrum and structure of carbony 1 fluoride, J. Mol. Spectrosc., 50, 182-201, 1974.

Farmer, C. B., and 0. F. Raper, High resolution Infrared spectroscopy from space: A preliminary report on the results of the Atmospheric Trace Molecule Spectroscopy (ATMOS) Experiment on Spacelab 3, NASA Conference Proceedings, "Spacelab 3 Mission Review", CP-2429, May, 1986.

Froidevaux, L., Photochemical modeling of the Earth's stratosphere, PhD thesis, California Institute of Technology, Pasadena, CA, 1983.

Hopper, M. J., J. W. Russell, and J. Overend, Vibrational intensities. XVI. $\mathrm{COF}_{2}, \mathrm{COC}_{2}$, and $\mathrm{COBr}_{2}$, J. Chem. Phys., 48, 3765-3772, 1968.

Mallinson, P. D., et al., Infrared spectra of carbonyl fluorides and general harmonic force field, Spectrochim. Acta, 31A, 143-159, 1975.

Modica, A. P., and R. R. Brochu, $\mathrm{COF}_{2}$ band Intensitites in the 2.0 to 6.0 micron region, $J$. Quant. Spectrosc. Radiat. Transfer, 9 , $1105-$ $1116,1969$.

Murcray, D. G., and A. Goldman, CRC Handbook of High Resolution Infrared Laboratory Spectra of Atmospheric Interest, CRC Press, Boca Raton, Fla., 1981 .

Murcray; D. G., et al., High Resolution Infrared Laboratory Spectra, Department of Physics, University of Denver, Denver, Co., 1984.

Rinsland, C. P., et al., Absolute intensity measurements of the $\left(11^{1} 0-00^{0} 0\right)$ band of ${ }^{12} \mathrm{C}^{16} \mathrm{O}_{2}$ at $5.2 \mathrm{\mu m}$, App1. Opt., 22, 3805-3809, 1983.

Rinsland, C. P., D. C. Benner, and V. Malathy Devi, Measurements of absolute line intensities in carbon dioxide bands near $5.2 \mathrm{\mu m}$, Appl. Opt., 24, 1644-1650, 1985.

Rinsland, et al., Evidence for the existence of the $802.7-\mathrm{cm}^{-1}$ band $Q$ branch of $\mathrm{HO}_{2} \mathrm{NO}_{2}$ in high resolution solar absorption spectra of the stratosphere, Geophys. Res. Lett., this issue, 1986.

Rothman, L. S., et al., AFGL atmospheric absorption line parameters compllation: 1982 edition, Appl. Opt., 22, 2247-2256, 1983a.

Rothman, L. S., et al., AFGL trace gas compilation: 1982 version, App1. Opt. , 22, 1616-1627, $1983 b$.

Rowland, F. S., and M. J. Molina, Chlorofluoromethanes in the environment, Rev. Geophys. Space Phys., 13, 1-35, 1975.

Sze, N. D., Stratospheric fluorine: A comparison between theory and measurements, Geophys. Res. Lett., 5, 781-783, 1978.

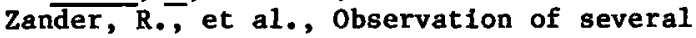
chlorine nitrate $\left(\mathrm{ClONO}_{2}\right)$ bands in stratospheric infrared spectra, Geophys. Res. Lett., this issue, 1986 .

L. R. Brown, C. B. Farmer, R. H. Norton, and 0. F. Raper, Jet Propulsion Laboratory, Californfa Institute of Technology, 4800 Oak Grove Drive, Pasadena, CA 91109.

R. Zander, Institute of Astrophysics, University of Llége, Liége-Ougree, Belglum.

J. H. Park, C. P. Rinsland, and J. M. Russell III, NASA Langley Research Center, Ma11 Stop 401A, Hampton, VA 23665.

(Recelved Apri1 25, 1986; accepted May 22, 1986.) 